\title{
The angiotensin converting enzyme inhibitors - alternative clinical applications
}

\author{
Beata Stanisz', Katarzyna Regulska², Miłosz Regulski ${ }^{3}$ \\ ${ }^{1}$ Chair and Department of Pharmaceutical Chemistry, Poznan University of Medical Sciences \\ ${ }^{2}$ Greater Poland Oncology Center \\ ${ }^{3}$ Chair and Department of Toxicology, Poznan University of Medical Sciences
}

\begin{abstract}
Angiotensin converting enzyme inhibitors have emerged as a useful strategy in the management of hypertension and other cardiovascular system-related diseases. However, a wide range of their biological effects has turned the scientific interest towards other possible clinical applications of these drugs. The present review demonstrates the available data on the reported angiotensin-converting enzyme inhibitors - based therapies in the treatment of the following human disturbances: cancer, obesity, Barrett syndrome, erythrocytosis, a high-dose-chemotherapyinduced cardiotoxicity, Marfan syndrome, Duchenne muscular dystrophy, migraine, Raynaud's syndrome and Alzheimer disease.
\end{abstract}

Key words: Renin-angiotensin system, off-label use, cancer.

\section{Introduction}

The renin angiotensin system (RAS) serves as one of the most important endogenous regulators of internal homeostasis. Its main functional enzymatic axis comprises renin that processes a liver-produced angiotensynogen to form angiotensin I and angiotensin converting enzyme (ACE) that hydrolyses angiotensin I to angiotensin II in the process that occurs mainly in the pulmonary circulation. Angiotensin II, in turn, being the primary RAS effector, interacts with its specific receptors $\left(A T_{1}, A T_{2}, A T_{3}\right.$ and $\left.A T_{4}\right)$ to induce pleiotropic biological actions that involve: vasoconstriction of arterioles, hypertension, release of aldosterone, increase of sodium and water reabsorption, release of vasopressin or sympathetic system stimulation. Importantly, these effects are particularly attributed to the systemic RAS that acts within an endocrine axis and responds to general body disturbances associated with water depletion and hypotension. What, however, needs to be emphasized is that apart from the circulatory RAS there are many tissue RAS systems which act in an autocrine/paracrine manner to regulate the structure and function of the corresponding target organs. Thus their actions are distinguished from the ones attributed to the circulatory RAS and they include: stimulation of cell proliferation and growth, inhibition of apoptosis, induction of angiogenesis as well as participation in pro-inflammatory and pro-migratory cellular responses [1, 2].

Given the significance of RAS in the regulation of cardiovascular system function, its blockade by pharmacological intervention occurred as an advantageous clinical approach in the treatment of its various pathologies. Indeed, angiotensin converting enzyme inhibitors (ACE-I), a popular class of antihypertensives, which act by the competitive inhibition of angiotensin converting enzyme leading to the abolishment of angiotensin II production, are commonly used in the treatment of a wide spectrum of cardiovascular and renal diseases, including: hypertension, congestive heart failure, left ventricular dysfunction after myocardial infarction, artherosclerotic vascular disease or insulindependent and non-insulin-dependent diabetic nephropathy. Specifically, this family of pharmaceuticals comprises several small-molecule compounds, the most 
important of which are: captopril, benazepril, enalapril, lisinopril, perindopril, ramipril, cilazapril, quinapril, imidapril, moexipril and trandolapril. In fact, their clinical efficiency has been confirmed in multiple randomized, controlled clinical trials which showed significant reductions of systolic and diastolic blood pressure in hypertensive patients after their use $[3,4,5]$. However, the family of ACE-I exhibits much more interesting pharmacological profile, associated with their multidirectional mode of action that, apart from the primary repression of angiotensin II signaling, additionally involves potentiation of bradykinin (by the inhibition of its degradation), increase of tissue nitric oxide and prostaglandins, inhibition of matrix metaloproteases, free-radical scavenging and generation of angiostatin. Important to mention that the latter two features are mainly attributed to the ACE-I containing a sulfhydryl moiety [1].

Hence, considering the pleiotropic nature of angiotensin II and the diversity of ACE-I-related actions, there is no surprise that these valuable pharmaceutical agents have been proposed as a potential therapeutic strategy in the management of several other human diseases with the inclusion of: cancer, obesity, Barrett syndrome, erythrocytosis, Marfan syndrome, Duchenne muscular dystrophy, migraine, Raynaud's syndrome or Alzheimer disease. In this review we analyze the available literature data on the off-label ACE-I use.

\section{Cancer}

The potential anti-cancer properties of ACE-I stem from their capability of decreasing angiotensin II, the potent stimulus of proliferation and growth. In fact, numerous experimental trials have confirmed the beneficial effect of various ACE-I on the reduction of tumor mass and number of metastases. Specifically, captopril exerted anti-proliferative and pro-apoptotic cell responses in lung and renal tumors $[1,6,7]$, enalapril - in human neuroblastoma cells [8] while captopril and trandolapril - in K562 leukemic cell line [9]. Furthermore, the affinity of ACE-I to matrix metaloproteases (MMP), especially MMP-2 and MMP-9 explains their anti-angiogenic and anti-migratory actions. Indeed, these effects have been confirmed for captopril, imidapril and lisinopril in the in vitro experiments [10, 11]. In addition to this captopril is known to inhibit tumor angiogenesis by the generation of angiostatin which is a potent, endogenous anti-angiogenic agent [1]. Enalapril, in turn, has been proven to stop cancer progression in the animal model of lung malignancy by the inhibition of TAM pro- genitors proliferation in the spleen and accumulation in lungs in the mechanism involving the S1P1 receptor signaling [12]. Also several epidemiological data support the introduction of ACE-I into anti-cancer therapy $[13,14,15]$. Nevertheless, due to the lack of appropriately-constructed, randomized clinical trials the utilization of the reviewed drugs in oncology still remains the question of future [1].

\section{Obesity}

The impact of ACE-I on the management of obesity is associated with the obesity-related chronic stimulation of systemic RAS as well as with the activation of local RAS system in adipose tissue in obese patients, which contributes to adipocyte growth and differentiation. Additionally, the overexpression of angiotensin II plays a crucial role in the development of the obesity-related hypertension, inflammation, insulin resistance, dyslipidemia and kidney disease collectively defined as a metabolic syndrome. Hence, there is no surprise that the blockade of RAS with ACE-I results in reduced body-weight, improved insulin sensitivity and the decreased serum levels of markers of inflammation. What is more ACE inhibitors have been proven effective in reducing blood pressure in obese humans $[16,17]$. Specifically, captopril has been suggested as an interesting therapeutic strategy for obesity, insulin resistance and inflammation [18]. Similarly, enalapril was found to reduce food intake and body fat in young normotensive rats [19].

\section{Bartter's syndrome}

Barrtter's syndrome is a rare disease described as an autosomal recesive tubulopathis, involving bilateral hyperplasia of juxtaglomerular apparatus that is responsible for an excessive renin production, hiperaldosteronism, elevated level of angiotensin II and severe hypokalaemia caused by a massive renal potassium loss. In general, the majority of therapeutic approaches in the management of this condition is focused on the normalization of serum potassium concentration by pharmacologic intervention. Interestingly, small doses of captopril have been reported to produce beneficial effects in patients with Barrtter's syndrome with concomitant good tolerance. What is more captopril can be also used in diagnostics of this disease together with scintigraphy $[20,21,22]$. Another ACE-I successfully used for correction of hypokalaemia in this disease was enalapril [23]. 


\section{Secondary erythrocytosis}

Erythrocytosis is defined as the absolute increase in the number of red cells, caused by their overproduction in bone marrow or by tissue hypoxia. In fact, several reports confirm the correlation between RAS activation and increased erythropoiesis associated with secondary erythrocytosis. Hence, the pharmacological blockade of RAS, especially in subjects at risk for secondary erythrocytosis development seems a reasonable therapeutic option. And indeed, as indicated by the clinical data, the implementation of ACE-I-based treatment causes a reduction in hemoglobin levels in a dose-dependent manner in the following groups of patients: individuals with heart failure or chronic obstructive pulmonary disease, patients undergoing hemodialysis, patients after cardiac surgery and kidney transplant [24].

\section{Marfan's syndrome}

Marfan's syndrome is a genetic disease affecting connecting tissue that might cause severe complications in heart vessels and aorta, manifested by their stiffness and dilation, which eventually leads to dissection and death [25]. Generally, the advantageous effect of ACE-I in patients with this disorder stems from their impact on the retardation of aortic enlargement progression. Specifically, perindopril has been found to reduce aortic stiffness and decrease its diameters in patients with the reviewed autosomal-dominant connective tissue disorder [26].

\section{Duchenne muscular dystrophy}

Duchenne muscular dystrophy is a genetic disorder caused by the lack of protein, dystrophin, which leads to muscle degeneration. A gradual decrease of myocardial function is one of the consequences of this condition [27]. Interestingly, ACE-I have been found to delay the progression of cardiomiopathy in dystrophic patients while the combination of ACE-I and beta blockers has provided a benefit of a long-term survival within this population of patients treated against heart failure $[28,29,30]$.

\section{Prevention of a high-dose-chemothe- rapy-induced cardiotoxicity}

As is well known, the intensive anticancer treatment is inherently accompanied by multiple serious side effects which compromise the effectiveness of this medical procedure. Specifically, chronic cardiotoxicity is the major reason for the limitation of athracyclines-based chemotherapy, which further affects patient survival. As a matter of the fact, an important role in the development of anthracycline-dependent cardiomiopathy is actually attributed to cardiac RAS, which indicates that the introduction of ACE-I into treatment could provide an effective prevention against chemotherapy-induced cardiac dysfunction. Indeed, in one clinical study the administration of enalapril to the patients at high risk of cardiac insufficiency receiving high-dose chemotherapy resulted in a reduced number of cardiac-related adverse events, prolonged patient survival and stabilization of cardiac function. The mechanism responsible for this effect could involve the enalapril-dependent decrease of systolic wall stress, reduction of afterload, atteuation of fibrosis, inhibition of cell apoptosis and free radical scavenging $[31,32,33,34]$.

\section{Migraine}

The relationship between migraine and RAS is generally not fully recognized yet some interesting observations indicate that the frequency of attacks without aura positively correlates with the activity of ACE. Also there are several literature reports showing that the administration of lisinopril substantially improves the incidence of headaches in hypertensive and normotensive patients suffering from this condition. Similarly, enalapril has been found to exert a clinically significant prophylactic effect in patients with migraine headaches. Unfortunately, the putative mechanism of action behind this pharmacological response remains unknown yet certain data indicate that it could be the result of the ACE-I-dependent altered sympathetic activity, decreased degradation of bradykinin, encephalin, and substance $P$, increased prostacyclin synthesis, and free radical scavenging $[35,36]$.

\section{Raynaud's syndrome}

The Raynaud's phenomenon is characterized by a reversible peripheral vasospasm in response to cold, which usually affects hands and feet. The pharmacotherapy of this clinical condition focuses on vasodilatation and in this case ACE-I seem to offer a promising mode of action. Unfortunately, the available clinical trials provide conflicting results with several reports that emphasize the improved digital blood circulation after long-term and acute treatment with captopril [37] and other ones that demonstrate no influence of 
captopril or enalapril on the severity or frequency of disease attacks [38,39]. Hence, it is currently believed that although ACE-I might provide some minor effect to alleviate the disease symptoms, they are not superior to the traditional treatments. Thus, the appropriate clinical trials are needed to conclusively establish the role of ACE-I in the management of Raynaud's phenomenon [40].

\section{Alzheimer disease}

The potential contribution of RAS to the development of Alzheimer disease stems from the local expression of this system in brain. In fact, there are several experimental data suggesting the participation of ACE in the metabolism of beta-amyloid protein, the reduction of which occurs in this pathology. Interestingly, the administration of ACE-I has been found beneficial in the prevention of dementia or cognitive decline in humans without any symptoms of dementia while in patients with amnestic mild cognitive impairment, ACE-I produced stabilization of cognitive function. Furthermore the administration of ACE-I to adults suffering from Alzheimer disease has been found to delay the rate of cognitive decline. Contrary to this there are other reports suggesting the ineffectiveness of ACE I in the treatment of this clinical condition, which indicates that the utility of these drugs in patients with Alzheimer disease remains questionable [41].

\section{Conclusion}

The diversity of biological actions determines the variety of possible ACE-I's clinical applications which reach far beyond the classically-accepted use in hypertension and the related cardiovascular diseases. The primary limitation, however, in the extension of their clinical indications is lack of appropriate, randomized, controlled, long-term clinical trials that could definitively confirm their utility in the management of the above reviewed diseases.

\section{Conflict of interest}

The authors declare no conflict of interest.

\section{References}

1. Regulska K, Stanisz B, Regulski M. The Renin-Angiotensin system as a target of novel anticancer therapy. Curr Pharm Des. 2013 Dec; 19(40):7103-25.
2. Paszun S, Stanisz B. Rys historyczny - nadciśnienie tętnicze, układ renina-angiotensyna i synteza pierwszego inhibitora enzymu konwertującego angiotensynę. Journal of Medical Science. 2008; 5(77):392-8.

3. Brown NJ, Vaughan DE. Angiotensin-Converting Enzyme Inhibitors. Circulation. 1998 Apr; 97 (14):1411-20.

4. Sica DA. The evolution of renin-angiotensin blockade: angiotensin-converting enzyme inhibitors as the starting point. Curr Hypertens Rep. 2010 Apr;12(2):67-73.

5. Oko A. Przydatność leków inhibitorów konwertazy angiotensyny i antagonistów wapnia w zapobieganiu postępującemu uszkodzeniu nerek. Journal of Medical Science. 1999; 5(68):467-76.

6. Attoub S, Gaben AM, Al-Salam S, Al Sultan MA, John A, Nicholls MG, Mester J, Petroianu G. Captopril as a potential inhibitor of lung tumor growth and metastasis. Ann NY Acad Sci. 2008 Sep; 1138:65-72.

7. Hii SI, Nicol DL, Gotley DC, Thompson LC, Green MK, Jonsson JR. Captopril inhibits tumour growth in a xenograft model of human renal cell carcinoma. $\mathrm{Br} J$ Cancer. 1998 Mar; 77(6):880-3.

8. Chen L, Re RN, Prakash O, Mondal D. Angiotensinconverting enzyme inhibition reduces neuroblastoma cell growth rate. Proc Soc Exp Biol Med. 1991 Mar; 196(3):280-3.

9. Haznedaroglu IC, Beyazit Y. Pathobiological aspects of the local bone marrow renin-angiotensin system: a review. Renin Angiotensin Aldosterone Syst. 2010 Dec; 11(4):205-13.

10. Yamamoto $D_{\text {, }}$ Takai $S$, Jin D, Inagaki S, Tanaka K, Miyazaki M. Molecular mechanism of imidapril for cardiovascular protection via inhibition of MMP-9. J Mol Cell Cardiol. 2007 Dec;43(6):670-6.

11. Kuntze LB, Antonio RC, Izidoro-Toledo TC, Meschiari CA, Tanus-Santos JE, Gerlach RF. Captopril and Lisinopril Only Inhibit Matrix Metalloproteinase-2 (MMP-2) Activity at Millimolar Concentrations. Basic Clin Pharmacol Toxicol. 2014 Mar; 114(3):233-9.

12. Cortez-Retamozo V, Etzrodt M, Newton A et al. Angiotensin II drives the production of tumor-promoting macrophages. Immunity. 2013 Feb; 38(2):296-308.

13. Wilop S, von Hobe S, Crysandt M, Esser A, Osieka R, Jost E. Impact of angiotensin I converting enzyme inhibitors and angiotensin II type 1 receptor blockers on survival in patients with advanced non-small-cell lung cancer undergoing first-line platinumbased chemotherapy. J Cancer Res Clin Oncol. 2009 Oct; 135(10):1429-35.

14. Kim ST, Park KH, Oh SC, Seo JH, Kim JS, Shin SW, Kim $\mathrm{YH}$. How does inhibition of the renin-angiotensin system affect the prognosis of advanced gastric cancer patients receiving platinum-based chemotherapy? Oncology. 2012 Oct; 83(6):354-60.

15. Yuge K, Miyajima A, Tanaka N, Shirotake S, Kosaka T, Kikuchi E, Oya M. Prognostic value of reninangiotensin system blockade in non-muscle-invasive bladder cancer. Ann Surg Oncol. 2012 Nov; 19(12):3987-93.

16. Segura J, Ruilope LM. Obesity, essential hypertension and renin-angiotensin system. Public Health Nutr. 2007 Oct;10(10A):1151-5.

17. Velkoska E, Warner FJ, Cole TJ, Smith I, Morris MJ. Metabolic effects of low dose angiotensin converting enzyme 
inhibitor in dietary obesity in the rat. Nutr Metab Cardiovasc Dis. 2010 Jan;20(1):49-55.

18. Premaratna SD, Manickam E, Begg DP, Rayment DJ, Hafandi A, Jois M, Cameron-Smith D, Weisinger RS. Angiotensin-converting enzyme inhibition reverses diet-induced obesity, insulin resistance and inflammation in C57BL/6J mice. Int J Obes (Lond). 2012 Feb;36(2):233-43.

19. Santos EL, de Picoli Souza K, Guimarães PB, Reis FC, Silva SM, Costa-Neto CM, Luz J, Pesquero JB. Effect of angiotensin converting enzyme inhibitor enalapril on body weight and composition in young rats. Int Immunopharmacol. 2008 Feb;8(2):247-53.

20. Dondi M, Fanti S, Monetti N.J. Bartter's syndrome: renal scintigraphic appearance after captopril administration. Nucl Med. 1996 Oct;37(10):1688-90.

21. T. Suzuki, M. Nangaku, S. Oku, H. Takemura, Y. Yokoyama, Y. Takahashi, T. Fujita. Captopril renography in Bartter's syndrome. Clin Exp Nephrol. 2002 Sep;6(3):0163-0165.

22. Colamussi P, Panareo S, Cittanti C, Giganti M, Filice A, Baresic T, El Maoued S, Rizzati R, Piffanelli A. Bartter's syndrome and captopril scintigraphy: a case report. Ann Nucl Med. 2003 Apr;17(2):149-52.

23. Hené RJ, Koomans HA, Dorhout Mees EJ, vd Stolpe A, Verhoef GE, Boer P. Correction of hypokalemia in Bartter's syndrome by enalapril. Am J Kidney Dis. 1987 Mar;9(3):200-5.

24. Leshem-Rubinow E, Steinvil A, Zeltser D, Berliner S, Rogowski O, Raz R, Chodick G, Shalev V. Association of angiotensin-converting enzyme inhibitor therapy initiation with a reduction in hemoglobin levels in patients without renal failure. Mayo Clin Proc. 2012 Dec;87(12):1189-95.

25. Dietz HC, Loeys B, Carta L, Ramirez F. Recent progress towards a molecular understanding of Marfan syndrome. Am J Med Genet C Semin Med Genet. 2005 Nov;139C(1):4-9.

26. Ahimastos AA, Aggarwal A, D'Orsa KM, Formosa MF, White AJ, Savarirayan R, Dart AM, Kingwell BA. Effect of perindopril on large artery stiffness and aortic root diameter in patients with Marfan syndrome: a randomized controlled trial. JAMA. 2007 Oct 3;298(13):1539-47.

27. Mendell JR, Sahenk Z, Prior TW. The childhood muscular dystrophies: diseases sharing a common pathogenesis of membrane instability. J Child Neurol. 1995 Mar;10(2):150-9.

28. Ogata $H$, Ishikawa $Y$, Ishikawa $Y$, Minami R. Beneficial effects of beta-blockers and angiotensin-converting enzyme inhibitors in Duchenne muscular dystrophy. J Cardiol. 2009 Feb;53(1):72-8.

29. Viollet L, Thrush PT, Flanigan KM, Mendell JR, Allen HD. Effects of angiotensin-converting enzyme inhibitors and/or beta blockers on the cardiomyopathy in Duchenne muscular dystrophy. Am J Cardiol. 2012 Jul;110(1):98-102.

30. Duboc D, Meune C, Pierre B, Wahbi K, Eymard B, Toutain A, Berard C, Vaksmann G, Weber S, Bécane HM. Perindopril preventive treatment on mortality in Duchenne muscular dystrophy: 10 years' follow-up. Am Heart J. 2007 Sep;154(3):596-602.
31. Cardinale D, Colombo A, Sandri MT, Lamantia G, Colombo N, Civelli M, Martinelli G, Veglia F, Fiorentini C, Cipolla CM. Prevention of high-dose chemotherapy-induced cardiotoxicity in high-risk patients by angiotensin -converting enzyme inhibition. Circulation. 2006 Dec; 5(23):2474-81.

32. Kalam K, Marwic TH. Role of cardioprotective therapy for prevention of cardiotoxicity with chemotherapy: A systematic review and meta-analysis. EJC. 2013 Sep;49(13):2900-9.

33. Blaes AH, Gaillard P, Peterson BA, Yee D, Virnig B. Angiotensin converting enzyme inhibitors may be protective against cardiac complications following anthracycline chemotherapy. Breast Cancer Res Treat. 2010 Jul;122(2):585-90.

34. Curigliano G, Cardinale D, Suter T, Plataniotis G, de Azambuja E, Sandri MT, Criscitiello C, Goldhirsch A, Cipolla C, Roila $\mathrm{F}$ and on behalf of the ESMO Guidelines Working Group. Cardiovascular toxicity induced by chemotherapy, targeted agents and radiotherapy: ESMO Clinical Practice Guidelines. Ann Oncol. 2012; 23(suppl 7):vii155-vii166.

35. Bender WI. ACE inhibitors for prophylaxis of migraine headaches. Headache. 1995 Sep;35(8):470-1.

36. Schrader H, Stovner LJ, Helde G, T Sand T, Bovim G. Prophylactic treatment of migraine with angiotensin converting enzyme inhibitor (lisinopril): randomised, placebo controlled, crossover study. BMJ. 2001 Jan;322(7277):19.

37. Challenor VF. Drugs. Angiotensin converting enzyme inhibitors in Raynaud's phenomenon. 1994 Dec;48(6):864-7.

38. Miyazaki S, Miura K, Kasai Y, Abe K, Yoshinaga K. Relief from digital vasospasm by treatment with captopril and its complete inhibition by serine proteinase inhibitors in Raynaud's phenomenon. Br Med J (Clin Res Ed). 1982 Jan;30(6312):310-11.

39. Challenor VF, Waller DG, Hayward RA, Griffin MJ, Roath OS. Subjective and objective assessment of enalapril in primary Raynaud's phenomenon. Br J Clin Pharmacol. 1991 Apr;31(4):477-80.

40. Wood HM, Ernst ME. Renin-angiotensin system mediators and Raynaud's phenomenon. Ann Pharmacother. 2006 Nov;40(11):1998-2002.

41. Soto ME, van Kan GA, Nourhashemi F, Gillette-Guyonnet $\mathrm{S}$, Cesari M, Cantet C, Rolland Y, Vellas B. Angiotensin-converting enzyme inhibitors and Alzheimer's disease progression in older adults: results from the Réseau sur la Maladie d'Alzheimer Français cohort. J Am Geriatr Soc. 2013 Sep;61(9):1482-8.

Correspondence address: Beata Stanisz phone: +48618546645 email: bstanisz@ump.edu.pl 